\title{
Pistas para renovar la antropología teológica desde una ecología integral $^{1}$
}

\author{
Clues to renew theological anthropology from an integral ecology
}

\author{
Román Guridi \\ Doctor en Teología \\ Pontificia Universidad Catolica de Chile \\ rguridisj@gmail.com \\ Fecha recepción:30/08/2019 \\ Fecha aceptación:08/11/2019
}

Como citar este artículo: R. GURIDI. "Pistas para renovar la antropología teológica desde una ecología integral. Lectio inauguralis magister en ciencias religiosas y filosóficas" en Palabra y Razón. Revista de Teología, Filosofía y Ciencias de la Religión $\mathrm{N}^{\circ} 16$, Diciembre 2019, pp. 9-22 https://doi.org/10.29035/pyr.16.9

Resumen: En el contexto de la crisis ecológica actual es crucial que nos interroguemos sobre el modo en que el cristianismo comprende al ser humano en su relación con la naturaleza, y las prácticas que se desprenden de esta comprensión. Esta Lectio inauguralis propone, por lo tanto, tres pistas para renovar la antropología teológica desde una ecología integral: un ser humano a) consciente de la crisis y de su participación en ella; b) atento a la comunidad de la creación que va más allá de su propia especie; y c) capaz de recuperar el verdadero sentido de la ascesis y de cultivar nuevos hábitos. Sin pretensión de exhaustividad, estas tres pistas antropológicas colaboran al discernimiento y búsqueda de nuevas narrativas teológicas que nos permitan avanzar decididamente hacia una cultura del cuidado de la casa común.

Palabras clave: ecoteología / antropología teológica / crisis ecológica / ascesis / Laudato Si'

Abstract: How Christianity understands human beings in their relationship with nature is a crucial question within the context of the current ecological crisis. Therefore, this Lectio inauguralis offers a threefold perspective to renovate theological anthropology from the viewpoint of an integral ecology: human beings a) aware of the crisis and their responsibility in it; b) attentive to the community of creation which goes beyond their own species; and c) able to retrieve the true meaning of asceticism and embody new habits. Without any claim to be exhaustive, these three anthropological clues can foster the discernment and search for new theological narratives that allow us to move decisively towards a culture of caring for our common home.

Key words: ecotheology / theological anthropology / ecological crisis / asceticism / Laudato Si'

\footnotetext{
${ }^{1}$ Lectio Inauguralis Magister en Ciencias Religiosas y Filosóficas. Universidad Católica del Maule, 27 de abril de 2019.
} 


\section{Introducción}

Muchas gracias por esta oportunidad de proponerles una conversación que me parece decisiva en los tiempos que estamos viviendo. Tiempos de crisis, donde se están desbarajustando equilibrios; tiempos de decisiones que no debiéramos postergar más; tiempos de cuestionamiento a nuestros modos cotidianos de vivir, a las relaciones que establecemos entre nosotros, y a la manera en que interactuamos con los demás seres y cosas. La conversación que quiero proponerles es sobre la crisis ecológica y algunos elementos cruciales que estamos necesitando como hombres y mujeres para apuntar a una cultura del cuidado. No quisiera de ningún modo aparecer como un profeta de calamidades ni desastres, sino movernos hacia una pregunta sencilla, pero al mismo tiempo profunda y necesaria en estos tiempos, ¿dónde estoy yo en relación con la crisis ecológica actual?

Para enmarcar lo que quiero proponerles, quisiera leerles unas líneas de una columna escrita hace unos años por Cristián Warnken a propósito del poema de Neruda "Alturas de Machu Picchu" y la actual crisis ecológica, y que se enfoca en una de las preguntas centrales de ese texto: ¿el hombre dónde estuvo?

Esa misma pregunta volvió a interpelarme hace unos días, pero en un sentido distinto al que la pensó Neruda. Y las ruinas esta vez no son las de Machu Picchu, sino nuestras propias ruinas futuras en las que se convertirán las grandes urbes y la tierra si la desertificación en curso, producto del cambio climático, no es revertida de manera radical, ahora, no mañana, porque mañana no existirá si el ser humano no se rebela contra una alienación peor que la testificada por Neruda y cuyo origen es la explotación inmisericorde de la naturaleza por el hombre, producto de nuestra "sociedad del rendimiento".

¿Dónde estuvo cada uno de nosotros cuando supimos que el agua era un bien escaso en el planeta y seguíamos regando nuestros insolentes jardines versallescos? ¿De qué sirve participar en seminarios sobre la huella de carbono, rotular productos con el sello "verde" o llevar a nuestros hijos a los "puntos verdes" a reciclar la basura si les dejaremos en herencia la tierra convertida en un gigantesco basural?

Cada uno en el lugar en que esté - sea político, empresario, o simple ciudadano debe hacerse esta pregunta a sí mismo, sin esconderse detrás del cómodo anonimato de la masa: "¿el hombre que soy dónde está?, ¿dónde estoy?" Solo nos salvaremos si asumimos individualmente y como colectivos de individuos conscientes la responsabilidad por estas ruinas y estos mares muertos, allí donde nuestros hijos buscarán desesperadamente algún día los restos de la humanidad perdida, o abrazarán llorando un árbol seco².

\footnotetext{
${ }^{2} \mathrm{http} / / /$ www.elmercurio.com/blogs/2016/05/12/41672/El-hombre-donde-esta.aspx consultado el $10 \mathrm{de}$ abril de 2019.
} 
Esta cita va directamente al punto central que les propongo: la pregunta por el ser humano. ¿Dónde estamos en relación con la crisis ecológica? ¿Dónde estoy yo frente a los desafíos ecológicos que enfrentamos en la actualidad? El papa Francisco en su encíclica Laudato Si', nos dice al hablar de la crisis socio-ambiental que "no se puede prescindir de la humanidad. No habrá una nueva relación con la naturaleza sin un nuevo ser humano. No hay ecología sin una adecuada antropología" ( $\left.{ }^{\circ} 118\right)$. Es decir, no haremos frente realmente y con profundidad a los desafíos ecológicos si no nos hacemos la pregunta sobre nuestra situación y transformación personal: ¿Dónde estoy yo? ¿Dónde está mi familia? ¿Dónde está la gente que me rodea, con la que interactúo? ¿Dónde está la Universidad Católica del Maule, en relación con los desafíos ecológicos que estamos enfrentando?

La alusión del papa al nuevo ser humano que se necesita es sugerente, justo en el momento en que la ciencia, especialmente en el área de la geología, se encuentra discutiendo si hemos entrado o no a una nueva era geológica llamada antropoceno (anthropos: hombre, y kainos: nuevo) ${ }^{3}$. Es decir, en el contexto de la crisis ecológica o de esta nueva era de la tierra, en la que somos conscientes de que el ser humano se ha transformado en una fuerza geológica capaz de alterar los sistemas y fuerzas naturales como el clima, la pregunta por el dónde estamos, a dónde queremos ir, y qué transformaciones debemos emprender, es clave.

Es doblemente clave porque una mala respuesta, es decir, una mala comprensión - parcial o errada - sobre el ser humano puede tener consecuencias desastrosas. El papa Francisco reconoce, por ejemplo, que "una presentación inadecuada de la antropología cristiana pudo llegar a respaldar una concepción equivocada sobre la relación del ser humano con el mundo. Se transmitió muchas veces un sueño prometeico de dominio sobre el mundo que provocó la impresión de que el cuidado de la naturaleza es cosa de débiles" ( $\left.{ }^{\circ} 116\right)$. Este es, de hecho, uno de los pocos números en que Laudato $\mathrm{Si}^{\prime}$ presta atención a lo que la creciente sensibilidad ecológica puede significar para el cristianismo en el sentido de examinar y eventualmente revisar ciertas afirmaciones teológicas y modos estereotipados de

\footnotetext{
${ }^{3}$ La tesis de fondo es que el ser humano se ha transformado en una fuerza capaz de alterarlo todo, incluso los sistemas biofísicos. Estas alteraciones incluyen, por ejemplo, los cambios en la composición química de la atmósfera, los océanos, y los suelos; el impacto de los gases de efecto invernadero en el clima; y la extinción masiva de especies. Acuñado por el ecólogo Eugene Stoermer a comienzos de 1980, el término antropoceno ha sido popularizado por el químico ambiental Paul Crutzen. Ver, por ejemplo, P. J. CRUTZEN, "Geology of Mankind," Nature 415, no. 6867 (January 2002): 23, y P. J. CRUTZEN y E. STOERMER, "The Anthropocene", IGBP Newsletter 41: 17-18. Para un análisis filosófico de esta noción, ver, por ejemplo, B. LATOUR, Facing Gaia: Eight Lectures on the New Climatic Regime, trans. Catherine Porter. Cambridge, UK ; Medford, MA: Polity, 2017. Para una mirada teológica ver, por ejemplo, C. DEANE-DRUMMOND, S. BERGMANN, and M. VOGT, eds., Religion in the Anthropocene. Eugene, OR: Cascade Books, 2017.
} 
hablar sobre el ser humano, sobre todo en su relación con el resto de las criaturas ${ }^{4}$. La encíclica parece afirmar, más bien, que, para hacer frente a los desafíos ecológicos desde la perspectiva de la teología, nos basta con recordar y clarificar la enseñanza tradicional de la Iglesia sobre la creación, la antropología, y el destino común de todas las criaturas. Esta línea de argumentación se centra en la tradición, y parece suponer que la crisis ecológica es simplemente una buena ocasión para recalcar ciertas ideas centrales de la fe cristiana. No obstante, la pregunta por el ser humano, y el modo en que la teología lo comprende en el contexto actual, son determinantes.

\section{Pistas para una comprensión adecuada del ser humano nuevo}

De este modo, la conexión entre la ecología y la antropología, y la importancia de una presentación adecuada de la doctrina cristiana sobre la humanidad - la idea del ser humano nuevo - inspiran y enmarcan esta presentación, que tiene como telón de fondo varias preguntas: ¿De qué manera puede la antropología teológica favorecer los cambios de comportamiento y mentalidad que tanto necesitamos hoy? ¿Cuáles son los recursos que eventualmente posee - imágenes, conceptos, e ideas más pertinentes para esto? ¿Cuál es la formulación más acertada de la antropología cristiana que no solo evite malas comprensiones, sino que desacredite claramente el supuesto mandato ilimitado dado al ser humano de someter al resto de las criaturas? Se trata de explorar, por lo tanto, las vías en que la antropología teológica pueda ser una fuente positiva de inspiración, y discernimiento para los creyentes en sus búsquedas de modos de vida ecológicamente amigables y en la promoción de una cultura del cuidado.

Les propongo tres pistas de comprensión del nuevo ser humano para el contexto actual, sin ninguna pretensión de ser exhaustivo: 1) Consciente de la crisis y de su participación en ella; 2) Atento a la comunidad de la creación que va más allá de su propia especie; 3) Capaz de recuperar el verdadero sentido de la ascesis y cultivar nuevos hábitos.

\section{a) Consciente de la crisis y de su participación en ella}

El nuevo ser humano es aquel que reconoce y comprende que estamos viviendo una crisis multidimensional y sistémica. Una crisis ecológica, en la que los problemas ambientales - como el cambio climático, el calentamiento global, la pérdida acelerada de biodiversidad, la necesaria equidad territorial, etc. - son solo la manifestación de

\footnotetext{
${ }^{4}$ Esta perspectiva aparece también en el $\mathrm{n}^{\circ} 200$ de la encíclica donde se dice que "si una mala comprensión de nuestros propios principios a veces nos ha llevado a justificar el maltrato a la naturaleza o el dominio despótico del ser humano sobre lo creado o las guerras, la injusticia y la violencia, los creyentes podemos reconocer que de esa manera hemos sido infieles al tesoro de sabiduría que debíamos custodiar".
} 
una crisis más amplia, que involucra falta de visión ética, imaginación, carácter, voluntad y liderazgo ${ }^{5}$. Asume - a pesar de todos los escepticismos y negaciones de turno - que estamos inmersos en una crisis ecológica; una crisis de un modo de vivir, de una manera de habitar el mundo, sostenida por ideas y actitudes cotidianas que están afectando negativamente a las personas, las sociedades, y también a la naturaleza. No es fácil admitir que estamos inmersos en una crisis. Laudato $\mathrm{Si}^{\prime}$ nos pone en guardia contra una ecología superficial o aparente "que consolida un cierto adormecimiento y una alegre irresponsabilidad", ya que como suele suceder en "épocas de profundas crisis [...] tenemos la tentación de pensar que lo que está ocurriendo no es cierto [...] este comportamiento evasivo nos sirve para seguir con nuestros estilos de vida, de producción y de consumo" ( $\left.{ }^{\circ} 59\right)$.

Tenemos que reconocer, por lo tanto, la raíz humana de la crisis $\left(\mathrm{n}^{\circ} 101\right)$, anclada en una comprensión errada de la vida y de nuestra acción en el mundo. Este modo de vivir que está en crisis está marcado, entre otras cosas, por la cultura del descarte $\left(\mathrm{n}^{\circ} 16,22,43\right)$; por el paradigma tecnocrático que penetra la economía y la política $\left(\mathrm{n}^{\circ} 107\right)$ e impone su lógica y objetivos en todas las dimensiones de nuestra vida; por el olvido de los fines de la acción humana $\left(\mathrm{n}^{\circ} 61,113,203\right)$; por una comprensión reductiva del desarrollo $\left(\mathrm{n}^{\circ} 147\right)$ y por la creencia equivocada en el progreso material sin límites $\left(n^{\circ} 78\right)$. Esta mirada global de la crisis se nutre, a su vez, de una comprensión englobante de la ecología como ecología integral'; ya que la ecología no se reduce a lo ambiental, sino que también incluye otras dimensiones que le son propias, como la social y la personal. De este modo, la ecología integral evidencia que son inseparables la preocupación por la naturaleza, la justicia con los pobres, el compromiso con la sociedad y la paz interior ( $\left.{ }^{\circ} 10\right)$. Así, al agregar el adjetivo "integral", el término ecología despliega mejor lo que le es propio: la

\footnotetext{
${ }^{5}$ Ver E. CONRADIE, "Towards an Agenda for Ecological Theology: An Intercontinental Dialogue," Journal for the Study of Religion, Nature and Culture 10, no. 3 (February 24, 2007): 286. Laudato $\mathrm{Si}^{\prime}$ también presenta una comprensión sistémica de la crisis. Señala, por ejemplo, que [...] la crisis ecológica es una eclosión o una manifestación externa de la crisis ética, cultural y espiritual de la modernidad" ( $\left.\mathrm{n}^{\circ} 119\right)$; y que "es fundamental buscar soluciones integrales que consideren las interacciones de los sistemas naturales entre sí y con los sistemas sociales. No hay dos crisis separadas, una ambiental y otra social, sino una sola y compleja crisis socio-ambiental. Las líneas para la solución requieren una aproximación integral para combatir la pobreza, para devolver la dignidad a los excluidos y simultáneamente para cuidar la naturaleza" $\left(\mathrm{n}^{\circ} 139\right)$.

${ }^{6}$ La noción de ecología integral aparece en los siguientes números de la encíclica: 10, 11, 62, 124, 137, $159,225,230$, y es especialmente desarrollada en el capítulo IV de la encíclica: 137-162. En las últimas décadas se han propuesto diversas tipologías desde la filosofía y la teología para mostrar la integralidad de la noción de ecología - que es más amplia y comprehensiva que la de ambiente o naturaleza - y para distinguir diversas dimensiones de la misma. Ver, por ejemplo, F. GUATTARI, Les Trois Ecologies. Editions Galilée, 2008. En el caso de la teología ver, por ejemplo, la tipología que propone Leonardo Boff para la ecología: ambiental, mental, social, e integral. Ver, por ejemplo, L. BOFF, La Dignidad de La Tierra. Ecología, Mundialización, Espiritualidad. La Emergencia de Un Nuevo Paradigma. Trotta: Madrid, 2000; La Voz Del Arcoiris. Trotta: Madrid, 2003; y La Opción-Tierra. La Solución Para La Tierra No Cae Del Cielo. Sal Terrae: Santander, 2008.
} 
interrelación entre todos los seres, y la vinculación estrecha entre las dimensiones personal, social, y medioambiental de la ecología ${ }^{7}$. Es el comportamiento cotidiano del ser humano el que está afectando justamente a estas tres dimensiones ecológicas.

Efectivamente, estamos en una crisis. Y crisis significa etimológicamente decisión. La crisis no está pasando, en primer lugar, allá "afuera" en la naturaleza, en los ríos, los océanos, el aire, o el clima. No se trata meramente de un supuesto colapso de sistemas naturales. La crisis está sucediendo en nuestra mente y en nuestro corazón; en nuestras maneras de pensar y sentir, y, por cierto, actuar. Está aconteciendo en nuestro interior; en nuestros modos de vivir y de relacionarnos que están siendo perjudiciales para nosotros mismos, para los demás, y para la naturaleza. Así lo afirmó con claridad Benedicto XVI al comienzo de su pontificado al señalar que los "desiertos exteriores se multiplican en el mundo porque se han extendido los desiertos interiores" ${ }^{\text {. }}$. Por lo tanto, tenemos que tomar una decisión ante los escenarios futuros que se vislumbran como consecuencia de nuestras prácticas y creencias actuales, tremendamente dañinas para las personas, las sociedades y la naturaleza. Esto se hace evidente, como señala Laudato $\mathrm{Si}^{\prime}$, en el clamor de la tierra $\mathrm{y}$ de los pobres $\left(\mathrm{n}^{\circ} 49,53\right)$.

Crisis también significa juicio. Y esta idea del "juicio", que es un importante tema bíblico, es utilizada por varios teólogos cristianos en su análisis de la crisis ecológica. En este mismo registro Laudato Si' enjuicia, por ejemplo, al poder político colonizado por las finanzas y resistente a impulsar ciertos cambios necesarios, preguntándole: “¿Para qué se quiere preservar hoy un poder que será recordado por su incapacidad de intervenir cuando era urgente y necesario hacerlo?" ( $\left.{ }^{\circ} 57\right)$. ¿Quiénes nos enjuician a nosotros? Me enjuicio quizás yo mismo, en primer lugar, por el uso que hago del tiempo, y mi dificultad para destinar momentos de calidad para estar con las personas que quiero; por dejarme llevar por el ritmo frenético de lo cotidiano, y por estar demasiado conectado y distraído de lo que me pasa o pasa a mi alrededor, mirando memes y compartiendo videos y stickers. Me enjuicio por estar obsesionado con una cierta comprensión del éxito que lo monetariza todo.

Nos enjuician también los descartados, los migrantes que no son bien recibidos; el clasismo y todas las dinámicas de apariencia entre nosotros; el ser

\footnotetext{
${ }^{7}$ Creemos que el papa Francisco echa mano nuevamente a un recurso utilizado antes en su exhortación apostólica Evangelii Gaudium. En ella utiliza la fórmula de una espiritualidad evangelizadora en salida, permitiéndole al término espiritualidad decir con mayor claridad algo que se nos ha oscurecido: que la espiritualidad verdadera es siempre un camino hacia afuera, que nos pone en contacto con la realidad, y se opone a las dinámicas de autorreferencialidad. En Laudato Si' el hecho de adjetivar la ecología como integral le permite insistir, contra las miradas parciales, en su carácter englobante y en la conexión profunda entre las esferas personal, social y medioambiental propias de la ecología.

${ }^{8}$ BENEDICTO XVI. Homilia en el solemne inicio del ministerio petrino (24 abril 2005): AAS 97 (2005), 710 .
} 
parte del machismo y actitudes cotidianas que denigran, atemorizan, o ridiculizan a las mujeres. Nos enjuician también los demás seres y cosas por no bajarnos del auto y colaborar a la emisión de gases de efecto invernadero. Me enjuician por mi exceso de consumo y la facilidad para deshacerme de las cosas; me enjuician por mi frivolidad e indiferencia ante los animales que son hacinados, maltratados, y masivamente asesinados para nuestros banquetes. El juicio, entonces, tiene que ver con la ecología en su triple dimensión - personal, social, y ambiental- reconociendo evidentemente las dimensiones estructurales - políticas y económicas- de los desafíos que enfrentamos, y que quedan claramente expuestas en nociones como la obsolescencia programada o la cultura del descarte.

El acto de reconocer que estamos en una crisis multidimensional y sistémica requiere que hagamos frente a lo que el filósofo francés Jacques Dupuy llama "el orgullo metafísico", que básicamente es la incredulidad ante la información que ya poseemos sobre las posibles consecuencias futuras de nuestro daño ecológico actual. Se trata de orgullo ya que, por una parte, no le creemos a la información que ya tenemos -no le damos crédito- $y$, por otra, pensamos que la ciencia y la técnica van a encontrar alguna solución a cada uno de los problemas que nos asechan y, por lo tanto, no hay verdaderamente necesidad de preocuparnos. Y es metafísico en la medida en que niega la consistencia real del futuro ya predicho, que está más allá de nuestra realidad actual. En diálogo con el pensamiento de Hans Jonas ${ }^{10}$, Dupuy afirma que lo que inmoviliza la toma de decisiones en el presente no es la incertidumbre con respecto a los escenarios futuros, sino que la no-creencia en las consecuencias previstas de nuestros proyectos o actividades actuales ${ }^{11}$. Es por eso que propone un "catastrofismo ilustrado" -catastrophisme éclairé-12 que, reivindicando el rol heurístico del temor, reconozca la existencia de ese futuro catastrófico ya pronosticado, para modificarlo desde la intervención en el presente. Necesitamos, por lo tanto, asumir lo que ya sabemos sobre el futuro.

\footnotetext{
${ }^{9}$ Ver J-P. DUPUY. Pour Un Catastrophisme Éclairé. Quand L'impossible Est Certain. Seuil: Paris, 2004, Petite métaphysique des tsunamis. Seuil: Paris, 2005, y "The precautionary principle and enlightened doomsaying," Revue de metaphysique et de morale $\mathrm{N}^{\circ}$ 76, no. 4 (2012): pp. 577-92.

${ }^{10}$ Ver H. JONAS. El Principio de Responsabilidad: Ensayo de Una Ética Para La Civilización Tecnológica. Herder: Barcelona, 1995.

${ }^{11}$ La no-creencia no responde a una mala voluntad, sino que a la dificultad para representarnos las consecuencias futuras de nuestros actos: "conocer estas amenazas, algunas de las cuales son muy graves, no mueve a la acción, ya que no creemos lo que sabemos, dado que no logramos representarnos las implicancias de lo que sabemos". J-P. DUPUY. Petite métaphysique des tsunamis, 22. (la traducción es mía)

${ }^{12}$ El catastrofismo ilustrado es, en opinión de Dupuy, "una actitud filosófica, una inversión de orden metafísico en nuestras maneras de pensar el mundo y el tiempo, que se basa en la temporalidad de las catástrofes". J-P. DUPUY. Pour Un Catastrophisme Éclairé. Quand l'impossible Est Certain, 80. (la traducción es mía)
} 


\section{b) Atento a la comunidad de la creación que va más allá de su propia especie}

Quisiera introducir el segundo punto que les propongo con una cita provocativa de un teólogo cristiano norteamericano fallecido hace una década: "La idea clásica de que la tierra, o incluso el universo, fue creado exclusivamente para los seres humanos es, en nuestra era científica, pecaminosamente arrogante, biológicamente ingenua, cosmológicamente tonta, y por lo tanto teológicamente insostenible"13. El ser humano nuevo - el que se requiere en este tiempo - es el que tiene presente y recuerda que él también es tierra y es parte de una comunidad más amplia que su propia especie: la comunidad de la creación. De hecho, ésta es la comunidad que necesitamos visibilizar, sacar del olvido, y respaldar en la actualidad. Nos dice el Papa Francisco en Laudato Si': "por eso, entre los pobres más abandonados y maltratados, está nuestra oprimida y devasta $\neg$ da tierra, que «gime y sufre dolores de parto» $(\mathrm{Rm} 8,22)$. Olvidamos que nosotros mismos so $\neg$ mos tierra (cf. Gn 2,7). Nuestro propio cuerpo está constituido por los elementos del planeta, su aire es el que nos da el aliento y su agua nos vivifica y restaura" $\left(\mathrm{n}^{\circ} 2\right)$.

El ser humano nuevo es consciente, y afirma como un elemento clave de la realidad la interconexión de todas las cosas. Todo está conectado afirma numerosas veces la encíclica Laudato $\mathrm{Si}^{\prime}$. Si todo está conectado e interrelacionado, entonces la humanidad depende no solo de otros seres, sino que también de sistemas naturales. No se trata de relaciones opcionales, sino que de relaciones que nos permiten a cada uno de nosotros nuestra constitución e identidad. Nos permiten ser quienes somos.

Esta mirada sobre el ser humano confronta tanto la imagen de una humanidad aislada del resto de las criaturas y de su entorno, como el énfasis unilateral en su singularidad - la idea de que somos distintos - frente a las demás especies. Es crucial que nos preguntemos, por ejemplo, ¿cómo debemos pensar al ser humano en relación con las plantas, insectos, pájaros, y animales, y con la tierra, los océanos, y la atmósfera que contiene y nutre la vida? ¿Somos realmente únicos a los ojos de Dios? ¿No cae esta pretensión en la trampa del antropocentrismo que, a partir de la búsqueda de alguna (s) característica (s) particular de los seres humanos, concluye que tenemos un lugar privilegiado dentro de la creación, y nos asigna un rol de gobierno y control? ${ }^{14}$

De este modo, para acercarnos teológicamente al ser humano en el contexto actual necesitamos, como señala la teóloga Sallie Mcfague, un doble movimiento:

\footnotetext{
${ }^{13}$ J. A. NASH, “Toward the Ecological Reformation of Christianity," Interpretation 50, no. 1 (1996): 8. (la traducción es mía)

${ }^{14}$ Para una presentación interesante de la unicidad humana desde la teología y la ciencia, ver J. WENTZEL van HUYSSTEEN. Alone in the World? Human Uniqueness in Science and Theology. Eerdmans: Michigan, 2006.
} 
necesitamos descentrar para volver a centrar el lugar de la humanidad dentro de la comunidad de la creación ${ }^{15}$. En primer lugar, la especificidad del ser humano su distinción o singularidad - debe ser entendida en clave de continuidad con el resto de las criaturas. Desde los puntos de vista, cosmológico, biológico, y etológico es innegable nuestro parentesco y estrecha conexión con los demás seres. Desde la perspectiva teológica tampoco se sostiene este separatismo absoluto dado que compartimos con todo el resto de la creación la condición de criatura ${ }^{16}$.

Este es el momento de descentramiento tan necesario en el presente, en el que pareciera hemos olvidado que nosotros mismos también somos tierra. Varios biblistas contemporáneos, entre ellos Richard Bauckham, muestran bien que el paradigma del dominio no es el único, ni siquiera el más importante, que propone la Biblia para retratar la relación del ser humano con el resto de las criaturas ${ }^{17}$. Más habitual es el paradigma de la comunidad de la creación, basado en la noción de que los seres humanos y todo el resto de la creación, a pesar de todas nuestras diferencias, constituimos una única comunidad entrelazada por el hilo común de haber sido creados por Dios. Este paradigma de la comunidad de la creación presente fundamentalmente en los capítulos finales del libro de Job, los salmos y los profetas- supone por parte del ser humano una profunda "humildad cósmica"18, a través de la cual reconoce que todas las criaturas alaban y dan gloria a Dios, y también mantienen una relación estrecha con el Creador sin la necesidad de ninguna mediación humana.

Esta perspectiva se encuentra presente también en la encíclica Laudato $\mathrm{Si}^{\prime}$, a través de una argumentación que responde a un enfoque sacramental. Señala que todas las criaturas son revelación y manifestación de lo divino (85), que en todo lo que existe hay un reflejo de Dios (87), y que la creación es el lugar de la presencia divina (88). Basándose en Santo Tomás la encíclica afirma que la bondad y riqueza de Dios no puede ser expresada por una sola criatura, sino que se requiere del conjunto del universo con sus múltiples relaciones (86). De este modo, todas las criaturas poseen un valor intrínseco independiente de su relación con los seres humanos (33, $69,140)$, dan gloria y bendicen a Dios por su sola existencia $(33,69)$, y tienen un mensaje particular que comunicar $(33,85)$. El mundo no es un problema a resolver,

\footnotetext{
${ }^{15}$ Sobre este punto ver S. MCFAGUE, "At Home on Earth," in The Body of God: An Ecological Theology. Fortress Press: Minneapolis, MN, 1993, pp. 99-129.

${ }^{16}$ Ver, por ejemplo, D. CLOUGH. "All God's Creatures: Reading Genesis on Human and Non-human Animals," en S.C. BARTON and D. WILKINSON eds. Reading Genesis after Darwin. Oxford University Press: Oxford, 2009, pp. 145-162.

${ }^{17}$ Ver, por ejemplo, R. BAUCKHAM. The Bible and Ecology: Rediscovering the Community of Creation (Waco, TX: Baylor University Press, 2010), y Living with Other Creatures: Green Exegesis and Theology (Waco, TX: Baylor University Press, 2011).

${ }^{18}$ BAUCKHAM, The Bible and Ecology, p. 44.
} 
es un misterio gozoso que debemos contemplar con jubilosa alabanza en cuanto nos refleja la hermosura y bondad de Dios (12). Este enfoque sacramental transparenta la conexión íntima entre todas las cosas.

El nuevo ser humano, entonces, asume esta perspectiva teocéntrica, y toma como punto de partida de su propia identidad y prácticas, su pertenencia y dependencia a la comunidad de la creación. Esto mismo es resaltado por la teóloga norteamericana Elizabeth Johnson, en un maravilloso libro:

"según esta visión hondamente teocéntrica, los seres humanos participamos con el resto de las especies en un mundo interdependiente fundamentalmente orientado a Dios. Estamos situados dentro, no por encima del magnífico círculo de la vida, cuyo centro y horizonte globalizador es el generoso Dios de la vida. Este es un grupo de parentesco que reúne a miembros muy diversos, con relaciones enormemente ricas y complejas entre ellos (...) Si los seres humanos nos definimos sobre todo como criaturas hermanas, el dominio, benévolamente entendido, se convierte en un rol dentro de la esfera más abarcadora de las relaciones comunitarias, que tienen más de recíprocas que de unidireccionales"19.

Sin embargo, este momento de descentramiento debe ser complementado por un momento de volver a centrar el rol y lugar del ser humano dentro de la comunidad de la creación. La conciencia de compartir con toda la realidad la misma condición creatural es crucial para una conversión ecológica, pero no es lo suficientemente fuerte para asegurar una transformación real en las mentes y estilos de vida de la gente. La imagen teológica del ser humano nuevo requiere más que eso para poder sacudir la imaginación de las personas y ayudarlas a discernir caminos hacia una vida ecológicamente amigable. Tal como señala Sallie McFague, "somos parte del todo, y necesitamos internalizar esa percepción como un primer paso para vivir con verdad y justicia en nuestro planeta. Sin embargo, necesitamos más que un sentido de unidad con la tierra para vivir apropiadamente en ella" ${ }^{20}$. De este modo, la reflexión teológica, en el contexto de la crisis ecológica, debe tener como uno de sus principales objetivos una comprensión adecuada del rol y lugar del ser humano dentro de la creación.

En este sentido, la afirmación de la pertenencia del ser humano a la comunidad de la tierra no significa divinizar la tierra ni negar el valor peculiar del ser humano, como resalta Laudato $\mathrm{Si}^{\prime}$ (90). Éste último posee una dignidad especialísima dentro

\footnotetext{
${ }^{19}$ E. A. JOHNSON. "Pregunta a las bestias". Darwin y el Dios del amor, trans. M. J. LOZANOGOTOR PERONA. Sal Terrae: Santander, España, 2015, p. 268.

${ }^{20}$ S. MCFAGUE. "Human Beings, Embodiment, and Our Home the Earth," in Reconstructing Christian Theology, ed. R. S. CHOPP and M. LEWIS TAYLOR. Fortress Press: Minneapolis, MN, 1994, p. 166. (La traducción es mía)
} 
de la creación $(43,65,81)$ que le confiere una responsabilidad particular hacia el resto de las criaturas. Desconocer o desvirtuar el valor propio de los seres humanos con sus capacidades y recursos - implica fragilizar el compromiso ecológico de los mismos. Es profundamente cierto que todas las criaturas formamos una gran familia universal bajo un mismo Padre, transparentamos algo del Creador, y poseemos un valor intrínseco. No obstante, la dignidad particular que tenemos los seres humanos nos asigna una responsabilidad ineludible de cuidar al resto de las criaturas, $\mathrm{y}$, por lo tanto, como señala Laudato $\mathrm{Si}^{\prime}$, debemos aprender a orientar, cultivar y limitar nuestro poder (78).

Un desafío importante para el lenguaje teológico es saber decir, por una parte, la pertenencia de la humanidad a la comunidad de la creación con la que comparte un mismo origen, una misma historia, y un mismo futuro y, al mismo tiempo, el lugar y rol particular de los seres humanos que los distingue y separa de las demás criaturas no solo desde el punto de vista práctico sino también ontológico. Es preciso preguntarse, por lo tanto, sobre las imágenes y nociones utilizadas para caracterizar la manera en que la humanidad debe relacionarse con el resto de la creación. En este punto, son ciertas las fortalezas, pero también - y muy especialmente - los límites y ambigüedades de una noción que se ha transformado en un modo de hablar casi por defecto: el ser humano es el administrador responsable de la creación. Aunque la noción de administración introduce un límite ético en la relación del ser humano con las demás criaturas, sigue dando a entender que la naturaleza es simplemente un recurso para el uso y beneficio humano ${ }^{21}$.

\section{c) Capaz de recuperar el verdadero sentido de la ascesis y cultivar nuevos hábitos}

Recuperar la ascesis, en cuanto ejercicio o práctica - y no en cuanto aspereza o contención - es el tercer elemento fundamental para la humanidad hoy ${ }^{22}$. Podría pensarse que el ascetismo es un término cargado de asociaciones negativas como la fuga mundi y la represión de la corporalidad, y, por lo tanto, sospechar que promueve actitudes dañinas para el cuerpo y una minusvaloración del mismo. Se asocia espontáneamente la ascesis con la renuncia al placer, la mortificación y el sacrificio. Sin embargo, nada tiene que ver con esto. No se trata de refrenar, controlar, y suprimir. La ascesis apunta, más bien, a explorar, discernir y desplegar.

\footnotetext{
${ }^{21}$ Para una buena presentación de diferentes posturas teológicas frente a las nociones de administración y administrador ver, R. J. BERRY, ed. Environmental Stewardship: Critical Perspectives, Past and Present. T\&T Clark: London; New York, 2006.

${ }^{22}$ Para un mayor desarrollo de este punto ver R. GURIDI. Ecoteología: Hacia un nuevo estilo de vida. Ediciones Universidad Alberto Hurtado: Santiago, Chile, 2018, pp. 282-97.
} 
La comprensión actual de la ascesis no debe reducirse solo a las prácticas propias de los monjes y eremitas de los comienzos de la vida religiosa: la retirada del mundo, la restricción de alimentos, ayunos, la privación del sueño, y la abstinencia sexual. Al contrario de lo que se cree, el ascetismo no es parte del pasado de la religión y las culturas, sino que es una experiencia y práctica bastante extendidas y diversas. En la actualidad, las tendencias ascéticas pueden ser reconocidas, por ejemplo, en diferentes esferas de nuestra vida tales como la cultura de la dieta, los nuevos modos de alimentación, y las rutinas de entrenamiento corpora ${ }^{23}$. Por una parte, el ideal corporal en términos de tonificación y delgadez hace que muchos desplieguen estrategias y conductas ligadas al ejercicio, la abstinencia y el autocontrol, para adecuarse a él. Por otra parte, aquellos que practican el veganismo o vegetarianismo se abstienen de la carne, poniendo su atención no en lo que aparentemente pierden, sino en lo que positivamente ganan en términos de integridad personal y cuidado de la naturaleza.

La ascesis se orienta a la práctica y la acción. Es un hacer diferente, y no meramente una nueva forma de comprender la realidad. Así como los monjes eremitas desplegaron en el pasado un modo de vida alternativo a través de un conjunto de prácticas consideradas históricamente como ascéticas, hoy debemos preguntarnos por el tipo de acciones cotidianas que podrían ayudarnos a encarnar un estilo de vida ecológicamente amigable. Éstas pueden relacionarse con el uso de la energía, el agua, la comida, y los medios de transporte. También, con nuestros patrones de consumo, el manejo de los desechos, el modo en que habitamos el espacio, y las formas en que establecemos nuestras interacciones sociales. Se trata de acciones concretas y, por lo tanto, transmisibles e imitables. Son acciones a explorar en la triple dimensión de la ecología: personal, social, y medioambiental.

Ahora, las prácticas ascéticas no son fines, sino medios hacia una nueva subjetividad, un modo distinto de vida en sociedad, y un universo simbólico alternativo ${ }^{24}$. Por eso, estas prácticas no son ascéticas en función de su austeridad o aspereza, sino que justamente en función de su propósito. Son siempre acciones deliberadas que buscan, por un lado, resistir o confrontar patrones culturales incuestionados, y así convertirse en una alternativa dentro de un contexto dominante. En la actualidad, debiéramos desplegar acciones cotidianas que testimonien mejor nuestra dependencia constitutiva hacia otras formas de vida, manifiesten nuestra pertenencia a la comunidad de la creación, y fomenten el cuidado humano necesario para el bienestar y florecimiento de las demás criaturas.

\footnotetext{
${ }^{23}$ Ver, por ejemplo, J. TWIGG. "Modern Asceticism and Contemporary Body Culture," en Beyond Pleasure: Cultures of Modern Asceticism, ed. E. PEETERS, L. VAN MOLLE, and K. WILS. Berghahn Books: New York, 2011, 227-44.

${ }^{24}$ Ver, por ejemplo, R. VALANTASIS. "A Theory of Asceticism, Revised," in The Making of the Self: Ancient and Modern Asceticism. Wipf \& Stock Pub: Eugene, Or, 2008, 101-16.
} 
En este sentido, las prácticas ascéticas no son meramente reactivas, sino que apuntan, por otro lado, a abrir nuevos horizontes para el modo de vida personal, las interacciones sociales, y la relación con la naturaleza. Es por eso que la ascesis no es una huida del mundo, sino más bien una actitud de compromiso y un modo de vida que implican el uso respetuoso, no el abuso, de la creación. Las prácticas ascéticas, así entendidas, lejos de apartar del mundo para cultivar la religiosidad personal, despliegan una acción política y social que conecta profundamente con los desafíos actuales.

El patriarca ortodoxo de Constantinopla, Bartolomé I señala que el ascetismo es un correctivo adecuado para nuestra cultura de derroche, en la medida en que contrarresta el egocentrismo, y fomenta nuestro sentido de gratitud y el redescubrimiento de la belleza ${ }^{25}$. El ascetismo es, en consecuencia, un camino hacia la libertad, un modo de liberación; Y el asceta es el que es libre. No está controlado por las actitudes que abusan del mundo. No está atado a las prácticas que usan a las demás formas de vida y a las demás personas. Tal como señala John Chryssavgis, "el objetivo de la ascesis es la moderación, no la represión; su contenido es positivo, no negativo. Apunta al servicio, no al egoísmo; a la reconciliación, no a la renuncia. Sin la ascesis, ninguno de nosotros es auténticamente humano"26.

Laudato $\mathrm{Si}^{\prime}$ también sintoniza con la necesidad de la ascesis al recordarnos que ésta "significa aprender a dar, y no simplemente renunciar. Es un modo de amar, de pasar poco a poco de lo que yo quiero a lo que necesita el mundo de Dios. Es liberación del miedo, de la avidez, de la dependencia" ( $\left.n^{\circ} 9\right)$. La ascesis que necesitamos en el presente, no es una invitación a mirar hacia el pasado ni mucho menos imitar acríticamente las prácticas de los eremitas del desierto. Se trata de discernir, más bien, las acciones concretas que puedan encarnar un modo de vida ecológicamente amigable. Tal como nos dice John Zizioulas, "necesitamos no una ética, sino un ethos. No un programa, sino una actitud y una mentalidad. No una legislación, sino una cultura"27. No basta con que modifiquemos nuestro modo de mirar la realidad. Necesitamos incorporar nuevos hábitos y actitudes cotidianas hacia el conjunto de la comunidad de la tierra.

Es en ese contexto que cabe justamente preguntarse por el ser humano nuevo que se requiere. Si recapitulo la reflexión que les he propuesto, el ser humano nuevo es aquel que es consciente de la crisis ecológica en la que estamos insertos y de su

\footnotetext{
${ }^{25}$ Ver J. CHRYSSAVGIS, ed. Cosmic Grace, Humble Prayer: The Ecological Vision of the Green Patriarch Bartholomew I, Revised Edition. Eerdmans: Grand Rapids, MI, 2009, 188-89.

${ }^{26}$ J. CHRYSSAVGIS. "A New Heaven and a New Earth: Orthodox Theology and an Ecological World View," The Ecumenical Review 62, no. 2 (2010), p. 218.

${ }^{27}$ Ver, JOHN METROPOLITAN OF PERGAMON. "Preserving God's Creation," en Christianity and Ecology, ed. E. BREUILLY and M. PALMER. Cassell: London ; New York, 1992, p. 61.
} 
participación no solo en la generación de ella, sino que en sus posibles soluciones. En la raíz de la crisis hay ciertas formas de vivir, de habitar el mundo, que están entrelazadas con formas de pensar. Es necesario, por lo tanto, repensar el modo en que entendemos la singularidad del ser humano - somos únicos a los ojos de Dios y comenzar nuestra mirada por la inserción del ser humano en una comunidad más amplia que su propia especie: la comunidad de la creación. Es desde esta comunidad que debemos desplegar nuevos hábitos y acciones, que se nutran de una ascesis ecológica, para pasar decididamente de una cultura del abuso, en todas sus formas, a una cultura del cuidado. 